\title{
Exact Analytical Solution for Suction and Injection Flow with Thermal Enhancement of Five Nanofluids over an Isothermal Stretching Sheet with Effect of the Slip Model: A Comparative Study
}

\author{
Emad H. Aly ${ }^{1,2}$ and Abdelhalim Ebaid ${ }^{3}$ \\ ${ }^{1}$ Department of Mathematics, Faculty of Science, King Abdulaziz University, Jeddah 21589, Saudi Arabia \\ ${ }^{2}$ Department of Mathematics, Faculty of Education, Ain Shams University, Roxy, Cairo 11757, Egypt \\ ${ }^{3}$ Department of Mathematics, Faculty of Science, University of Tabuk, Tabuk 71491, Saudi Arabia
}

Correspondence should be addressed to Emad H. Aly; emad-aly@hotmail.com

Received 8 August 2013; Revised 29 August 2013; Accepted 30 August 2013

Academic Editor: Mohamed Fathy El-Amin

Copyright (C) 2013 E. H. Aly and A. Ebaid. This is an open access article distributed under the Creative Commons Attribution License, which permits unrestricted use, distribution, and reproduction in any medium, provided the original work is properly cited.

\begin{abstract}
We introduced a direct and effective approach to obtain the exact analytical solution for the nanoparticles-water flow over an isothermal stretching sheet with the effect of the slip model. In particular, we examined and compared the effect of the existence of five metallic and nonmetallic nanoparticles, namely, Silver, Copper, Alumina, Titania, and Silicon Dioxide, in a base of water. The most interesting physical parameters were then discussed in the presence of no-slip model, first order slip, and second order slip parameters. It is found that, with no-slip effect, the present exact solutions are in a very good agreement with the previous published results. On the other hand, with the effect of the slip model, increase in the nanoparticle volume friction decreases the velocity for the high density of nanoparticles, increases it for the low density of them, and increases the temperature for all investigated nanoparticles. Further, increase in the wall mass decreases the velocity and temperature; however, it increases the local skin friction. Furthermore, increase in the slips slows down the velocity, increases the temperature with an impressive effect in the injection case, and decreases the local skin friction and the reduced Nusselt number. It was also demonstrated that, as the nanoparticle becomes heavier, this results in increase and decrease in reduced skin friction coefficient and reduced Nusselt number, respectively, with significant effect in the presence of the second slip. Finally, Silver is the suitable nanoparticle if slowing down the velocity and increasing the temperature are needed; Silicon Dioxide is the appropriate nanoparticle if different behavior is to be considered.
\end{abstract}

\section{Introduction}

Because of its numerous applications, the problem of flow and heat transfer in boundary-layer over a stretching surface has attracted many researchers. Examples of these applications are metallurgical processes, such as drawing of continuous filaments through quiescent fluids, annealing and tinning of copper wires, glass blowing, manufacturing of plastic and rubber sheets, crystal growing, and continuous cooling and fiber spinning [1]. Further, there are wide range of applications in many engineering processes, such as polymer extrusion, wire drawing, continuous casting, manufacturing of foods and paper, glass fiber production, stretching of plastic films, and many others. In particular, during the manufacture of these sheets, the melt issues from a slit and is subsequently stretched to achieve the desired thickness. Hence, the final product with the desired characteristics strictly depends upon the stretching rate, the rate of cooling in the process, and the process of stretching [2]. Therefore, the choice of a proper cooling/heating liquid is essential as it has a direct impact on the rate of heat transfer.

The pioneer studies of stretching sheets were done by Sakiadis [3,4] for a moving, inextensible sheet and later extended by Crane [5] to a fluid flow over a linearly stretched 
sheet. Following the classical boundary-layer theory, many properties were later investigated using the no-slip condition on the wall. However, when the fluid is particulate such as emulsions, suspensions, foams, and polymer solutions, the no-slip condition is inadequate [6]. In such cases, investigations show that the no-slip condition is no longer valid, specially at the micro- and nanoscale, and instead, a certain degree of tangential slip must be allowed [7]. In particular, the fluid flow behaviour deviates significantly from the traditional no-slip flow. Therefore, in the recent years, the interest has been given to the study of this type of flow and some useful results have been recently introduced by many authors, as mentioned in the next paragraphs.

Convective heat transfer in nanofluids is a topic of major contemporary interest both in applied sciences and engineering, where a very good review was presented by Wang and Mujumdar [8,9] and Saidur et al. [10]. Choi [11] may be the first author to introduce the word "nanofluid" that represents the fluid in which nanoscale particles (diameter $<50 \mathrm{~nm}$ ) are suspended in the base fluid. With the rapid advances in nanotechnology, many inexpensive combinations of liquid/particles are now available. The base fluids used are usually water, ethylene glycol, toluene, and oil. Recent research on nanofluids showed that nanoparticles changed the fluid characteristics because thermal conductivity of these particles was higher than convectional fluids. Nanoparticles are of great scientific interest as they are effectively a bridge between bulk materials and atomic or molecular structures. The common nanoparticles that have been used are Aluminum, Copper, Silver, and Titanium or their oxides. Experimental studies by Eastman et al. [12] and Xuan and Li [13] showed that even with the small volumetric fraction of nanoparticles (usually $<5 \%$ ), the thermal conductivity of the base liquid can be enhanced by $10-20 \%$. The enhanced thermal conductivity of nanofluids together with the thermal conductivity of the base liquid and turbulence induced by their motion contributes to a remarkable improvement in the convective heat transfer coefficient. Further, Majumder et al. [14] showed experimentally that nanofluidic flow usually exhibits partial slip against the solid surface, which can be characterized by the so-called slip length (around 3.4-68 micrometers for different liquids). Therefore, the no-slip condition is no longer valid for fluid flows at the micro- and nanoscale.

In addition to the above discussion about the slip model, Noghrehabadi et al. [15] discussed the effect of partial slip boundary condition on the flow and heat transfer of nanofluids past stretching sheet at constant wall temperature to extend the work done by Khan and Pop [16]. Nandeppanavar et al. [17] have tabulated the literature of the first order slip; consequently Fang et al. [18] only considered the effect of the second order slip on the flow on a shrinking sheet. Hence, the paper by Nandeppanavar et al. [17] may be the first work to investigate the analysis of second order slip flow and heat transfer over a stretching sheet. Recently, Turkyilmazoglu [19] has analytically studied the heat and mass transfer of magnetohydrodynamic second order slip flow. He has mentioned that there exists a unique solution for any combination of the considered parameters if the stretching sheet is considered. Very recently, Roşca and Pop
[20] investigated the steady flow and heat transfer over a vertical permeable stretching/shrinking sheet with a second order slip being investigated using a second order slip flow model. This very important study showed clearly that the second order slip flow model is necessary to predict the flow characteristics accurately.

To show the enhancement of using nanofluids in comparison with pure base fluid, Yacob et al. [21] compared numerically the thermal enhancement of two types of nanofluids, namely, $\mathrm{Ag}$-water and $\mathrm{Cu}$-water, over an impermeable stretching sheet. In addition, with the effect of magnetic field, Hamad [22] studied boundary layer and heat transfer of nanofluids over impermeable isothermal stretching sheet for the metallic and metallic oxide nanoparticles. Further, Noghrehabadi et al. [23] examined theoretically the flow and heat transfer of two types of nanofluids, namely, Silver water and Silicon Dioxide water. They solved the governing equations by applying a combination of a symbolic power series and Padé approximation method. Very recently, Vajravelu et al. [24] studied the effect of variable viscosity on the flow and heat transfer of viscous Ag-water and $\mathrm{Cu}$-water nanofluids. They indicated that nanoparticle volume fraction is to increase the heat transfer and hence enhance the thermal boundary-layer thickness.

The aim of this work is to introduce a direct and effective approach to analytically obtain the exact solution for the flow over an isothermal stretching sheet with effect of no-slip, first order slip parameter, and second order slip parameter. In addition, it is to examine the effect of the existence of the most five common nanoparticles, namely, Silver, Copper, Alumina, Titania, and Silicon Dioxide, in a base of water. Further, we discuss the interested physical parameters, that is, the velocity, temperature, reduced skin friction coefficient, and reduced Nusselt number. The structure of the paper is as follows. Description of the problem, basic equations, and similarity solution are presented in Section 2. In Section 3, second, third, and fourth degree algebraic equations, including the investigated parameters, are governed on deducing the exact solution of the flow with no, first order, and second order slips, respectively. In addition, exact analytical solution of the temperature equation, represented in a simple gamma function, is proposed in the same section. This research is to be considered as an extension to the work done by Hamad [22] and Noghrehabadi et al. [23], besides the comparison with Wang [25] and Reddy Gorla and Sidawi [26] in the special cases.

\section{Governing System of Equations}

2.1. Description of the Problem. Consider a two-dimensional incompressible, laminar, and steady boundary-layer flow past an isothermal stretching sheet coinciding with the plane $y=$ 0 , with the flow being confined to $y>0$. This sheet is in a water-based nanofluids, which can contain different volume fractions of nanofluids, such as Silver (Ag), Silicon Dioxide $\left(\mathrm{SiO}_{2}\right)$, Copper $(\mathrm{Cu})$, Alumina $\left(\mathrm{Al}_{2} \mathrm{O}_{3}\right)$, and Titania $\left(\mathrm{TiO}_{2}\right)$. In addition, we assume that the $[15,17]$

(i) sheet surface has temperature at the wall $T_{w}$ and at ambient fluid $T_{\infty}$, where $T_{w}>T_{\infty}$; 
(ii) base fluid (i.e., water) and the nanoparticles are in a thermal equilibrium;

(iii) fluid outside the boundary layer is quiescent and stretching sheet velocity is linear;

(iv) velocity of the sheet is $U_{w}(x)=c x$, where $c>0$ is the stretching constant and $x$ is the coordinate measured along the stretching surface.

The thermophysical properties of the base fluid and nanoparticles are given in Table 1 .

2.2. Basic Equations. Under the above assumptions, the governing boundary-layer equations of the considered nanofluid (continuity, momentum, and energy) can be written, respectively, in the dimensional form as

$$
\begin{gathered}
\frac{\partial u}{\partial x}+\frac{\partial v}{\partial y}=0 \\
u \frac{\partial u}{\partial x}+v \frac{\partial u}{\partial y}=\frac{\mu_{n f}}{\rho_{n f}} \frac{\partial^{2} u}{\partial y^{2}}, \\
u \frac{\partial T}{\partial x}+v \frac{\partial T}{\partial y}=\frac{k_{n f}}{\left(\rho C_{p}\right)_{n f}} \frac{\partial^{2} T}{\partial y^{2}},
\end{gathered}
$$

where $(x, y)$ denotes the Cartesian coordinates along the sheet and normal to it, $u$ and $v$ are the velocity components of the nanofluid in the $x$-and $y$-directions, respectively, $p$ is the pressure of the nanofluid, $T$ is the temperature of the nanofluid, $C_{p}$ is the specific heat at constant pressure, $\rho_{n f}$ is the effective density, $\mu_{n f}$ is the effective dynamic viscosity, $\left(\rho C_{p}\right)_{n f}$ is the heat capacitance, and $k_{n f}$ is the thermal conductivity, where $(\sim)_{n f}$ denotes the nanofluid and is defined as follows [28, 29]:

$$
\begin{gathered}
\rho_{n f}=(1-\phi) \rho_{f}+\phi \rho_{s}, \\
\mu_{n f}=\frac{\mu_{f}}{(1-\phi)^{2.5}}, \\
\left(\rho C_{p}\right)_{n f}=(1-\phi)\left(\rho C_{p}\right)_{f}+\phi\left(\rho C_{p}\right)_{s}, \\
k_{n f}=\frac{\left(k_{s}+2 k_{f}\right)-2 \phi\left(k_{f}-k_{s}\right)}{\left(k_{s}+2 k_{f}\right)+\phi\left(k_{f}-k_{s}\right)} k_{f},
\end{gathered}
$$

where $\phi$ is the solid volume fraction, $\mu_{f}$ is the dynamic viscosity, $\rho_{f}$ and $\rho_{s}$ are the densities, $\left(\rho C_{p}\right)_{f}$ and $\left(\rho C_{p}\right)_{s}$ are the heat capacitances, and $k_{f}$ and $k_{s}$ are the thermal conductivities, where $(\sim)_{f}$ and $(\sim)_{s}$ denote the basic fluid and solid fractions, respectively. The appropriate boundary conditions of (1)-(3) are as follows:

$$
\begin{gathered}
u=U_{w}(x)+U_{\text {slip }}, \quad v=v_{w}(x), \\
T=T_{w}(x) \quad \text { at } y=0, \\
u=v=0, \quad T \longrightarrow T_{\infty}, \quad \text { as } y \longrightarrow \infty,
\end{gathered}
$$

where $U_{\text {slip }}$ is the slip velocity introduced in the next section.
2.3. Slip Model. In the present work, we consider Wu's slip model [30] (valid for arbitrary Knudsen number, $K_{n}$ ) which is given by

$$
\begin{aligned}
U_{\text {slip }}= & \frac{2}{3}\left(\frac{3-\alpha_{m} l^{3}}{\alpha_{m}}-\frac{3}{2} \frac{1-l^{2}}{K_{n}}\right) \lambda_{m} \frac{\partial u}{\partial y} \\
& -\frac{1}{4}\left[l^{4}+\frac{2}{K_{n}^{2}}\left(1-l^{2}\right)\right] \lambda_{m}^{2} \frac{\partial^{2} u}{\partial y^{2}}=A \frac{\partial u}{\partial y}+B \frac{\partial^{2} u}{\partial y^{2}},
\end{aligned}
$$

where $l=\min \left[1 / K_{n}, 1\right]$ and $0 \leq \alpha_{m} \leq 1$ and $\lambda_{m}$ are the momentum accommodation and molecular mean free path, respectively. Based on the definition of $l$, it is noticed that for any given value of $K_{n}$, we have $0 \leq l \leq 1$. Therefore, the molecular mean free path is always positive. Therefore, we know that $B<0$, and hence the second term in the right hand side of (6) is a positive number.

2.4. Similarity Solution. The dimensionless variables can be introduced as follows [22, 31]:

$$
\eta=y \sqrt{\frac{c}{v}}, \quad f(\eta)=\frac{\psi}{x \sqrt{c v}}, \quad \theta(\eta)=\frac{T-T_{\infty}}{T_{w}-T_{\infty}},
$$

where $\eta$ is the similarity variable, $f(\eta)$ is the dimensionless stream function, and $\theta(\eta)$ is the dimensionless temperature. Further, $\psi$ is the stream function which is defined in the usual way as $u=\partial \psi / \partial y$ and $v=-\partial \psi / \partial x$ to identically satisfy (1). From (7), we therefore obtain

$$
u=c x f^{\prime}(\eta), \quad v=-\sqrt{c v} f(\eta),
$$

where the prime denotes differentiation with respect to $\eta$. Hence, the mass transfer velocity at the wall becomes

$$
v_{w}=-\sqrt{c v} f(0) .
$$

Now on substituting (7) and (8) into (2) and (3), we obtain the following nonlinear ordinary differential equations:

$$
\begin{gathered}
\frac{1}{(1-\phi)^{2.5}\left[(1-\phi)+\left(\phi \rho_{s} / \rho_{f}\right)\right]} f^{\prime \prime \prime}(\eta) \\
+f(\eta) f^{\prime \prime}(\eta)-f^{\prime 2}(\eta)=0, \\
\frac{1}{\operatorname{Pr}} \frac{k_{n f} / k_{f}}{(1-\phi)+\phi\left(\rho C_{p}\right)_{s} /\left(\rho C_{p}\right)_{f}} \theta^{\prime \prime}(\eta)+f(\eta) \theta^{\prime}(\eta)=0,
\end{gathered}
$$

where $\operatorname{Pr}=v\left(\rho C_{p}\right)_{f} / k_{f}$ is the Prandtl number. The boundary conditions (5) then turn into

$$
\begin{gathered}
f(0)=s, \quad f^{\prime}(0)=1+\delta_{1} f^{\prime \prime}(0)+\delta_{2} f^{\prime \prime \prime}(0), \\
\theta(0)=1, \quad f^{\prime}(\eta) \longrightarrow 0, \\
\theta(\eta) \longrightarrow 0 \quad \text { as } \eta \longrightarrow \infty,
\end{gathered}
$$

where $s\left(=-v_{w} / \sqrt{c v}\right)$ is the wall mass transfer parameter, which refers to the suction and injection when $s>0$ and $s<0$, respectively, and $0<\delta_{1}(=A \sqrt{c / v})$ and $0>\delta_{2}(=$ $B c / v)$ are the first order slip and second order slip parameters, respectively. 
TABLE 1: Thermophysical properties of the base fluid and nanoparticles [27].

\begin{tabular}{lcccccc}
\hline Physical properties & Fluid phase (water) & $\mathrm{Ag}$ & $\mathrm{Cu}$ & $\mathrm{TiO}_{2}$ & $\mathrm{Al}_{2} \mathrm{O}_{3}$ & $\mathrm{SiO}_{2}$ \\
\hline$C_{p}(\mathrm{~J} / \mathrm{kg} \mathrm{K})$ & 4179 & 235 & 385 & 686.2 & 765 & 765 \\
$\rho\left(\mathrm{kg} / \mathrm{m}^{3}\right)$ & 997.1 & 10500 & 8933 & 4250 & 3970 \\
$k(\mathrm{~W} / \mathrm{m} \mathrm{K})$ & 0.613 & 429 & 401 & 8.9538 & 3970 \\
\hline
\end{tabular}

2.5. The Quantities of Practical Interest. In this type of study, it should be noted that the quantities of practical interest are the skin friction coefficient $C_{f}$ and local Nusselt number $\mathrm{Nu}$, which are defined as

$$
C_{f}=\frac{\tau_{w}}{\rho_{f} U_{w}^{2}}, \quad \mathrm{Nu}=\frac{x q_{w}}{k_{f}\left(T_{w}-T_{\infty}\right)},
$$

where $\tau_{w}$ and $q_{w}$ are the skin friction, or the shear stress, and heat flux from the surface, respectively, which are given by

$$
\tau_{w}=-\mu_{n f}\left(\frac{\partial u}{\partial y}\right)_{y=0}, \quad q_{w}=-k_{n f}\left(\frac{\partial T}{\partial y}\right)_{y=0} .
$$

Therefore, on using (7) and (8) in (12) and (13), the reduced skin friction coefficient and reduced Nusselt number $[22,31]$ are

$$
\begin{gathered}
C_{f}\left(\operatorname{Re}_{x}\right)^{1 / 2}=\frac{1}{(1-\phi)^{2.5}} f^{\prime \prime}(0), \\
\mathrm{Nu}\left(\operatorname{Re}_{x}\right)^{-1 / 2}=-\frac{k_{n f}}{k_{f}} \theta^{\prime}(0),
\end{gathered}
$$

where $\mathrm{Re}_{x}=c x^{2} / v$ is the local Reynolds number based on the stretching velocity.

\section{Exact Solution}

Equations (2) and (3) can be rewritten as

$$
\begin{gathered}
\lambda f^{\prime \prime \prime}+f f^{\prime \prime}-f^{\prime 2}=0, \\
\tau \theta^{\prime \prime}+f \theta^{\prime}=0,
\end{gathered}
$$

where

$$
\begin{gathered}
\lambda=\frac{(1-\phi)^{-2.5}}{1-\phi+\phi\left(\rho_{s} / \rho_{f}\right)}, \\
\tau=\frac{\left(\left(k_{s}+2 k_{f}\right)-2 \phi\left(k_{f}-k_{s}\right)\right) /\left(\left(k_{s}+2 k_{f}\right)+\phi\left(k_{f}-k_{s}\right)\right)}{\operatorname{Pr}\left(1-\phi+\phi\left(\left(\rho C_{p}\right)_{s} /\left(\rho C_{p}\right)_{f}\right)\right)}
\end{gathered}
$$

which is exactly solved, subject to the boundary conditions (11) in the next sections.

3.1. Exact Solution of the Flow: $f(\eta)$. Following the spirit analysis as introduced by Wang [32] and, Aly and Ebaid $[33,34]$, the exact solution of $f$ equation can be deduced as follows:

$$
f(\eta)=a+b e^{-\beta \eta}, \quad \text { where } a=\lambda \beta, b=s-a,
$$

which satisfies (15) and the first condition in (11). Further, from the second condition in (11), the parameter $\beta$ satisfies algebraic equations for three models discussed in the next three subsections.

3.1.1. No Slips: $\delta_{1}=\delta_{2}=0$. When there is no slip between the base fluid and nanoparticles, that is, $\delta_{1}=\delta_{2}=0$, then $\beta$ satisfies the following second degree algebraic equation:

$$
\lambda \beta^{2}-s \beta-1=0 \Longrightarrow \beta=\frac{s \pm \sqrt{s^{2}+4 \lambda}}{2 \lambda} .
$$

This expressions is more easier than those given in [17-19, 23].

3.1.2. Effect of the First Slip Only: $\delta_{2}=0$. If the first order slip is only to be considered, then $\beta$ has to achieve the following third degree algebraic equation:

$$
\delta_{1} \lambda \beta^{3}+\left(\lambda-\delta_{1} s\right) \beta^{2}-s \beta-1=0
$$

By solving (20) and taking into account Descartes' rule of signs and from the fact that $\delta_{1}>0$ and $\lambda>0$, there is only one positive root; see Van Gorder et al. [35].

3.1.3. Effect of the Second Slip: $\delta_{1} \neq 0, \delta_{2} \neq 0$. In this case, $\beta$ satisfies the following fourth degree algebraic equation:

$$
\delta_{2} \lambda \beta^{4}-\left(\delta_{1} \lambda+\delta_{2} s\right) \beta^{3}+\left(\delta_{1} s-\lambda\right) \beta^{2}+s \beta+1=0 .
$$

Following the analysis in [19], the corresponding four roots of (21) are given by

$$
\beta=\left\{\begin{array}{c}
\frac{1}{4 \delta_{2} \lambda}\left[\delta_{1}+\delta_{2} \lambda\left(s \mp \sqrt{12 \beta_{3}-\frac{\beta_{4}}{\sqrt{\beta_{6}}}-4 \beta_{6}}\right)\right. \\
\left.-2 \delta_{2} \lambda \sqrt{\beta_{6}}\right], \\
\frac{1}{4 \delta_{2} \lambda}\left[\delta_{1}+\delta_{2} \lambda\left(s \mp \sqrt{12 \beta_{3}+\frac{\beta_{4}}{\sqrt{\beta_{6}}}-4 \beta_{6}}\right)\right. \\
\left.+2 \delta_{2} \lambda \sqrt{\beta_{6}}\right],
\end{array}\right.
$$


with the following dummy variables:

$$
\begin{gathered}
\beta_{1}=27 s^{2} \delta_{2} \lambda-72 \delta_{2} \lambda\left(\delta_{1} s-\lambda\right)+2\left(\delta_{1} s-\lambda\right)^{3} \\
+9 s\left(\delta_{1} s-\lambda\right)\left(\delta_{1} \lambda+\delta_{2} s\right)+27\left(\delta_{1} \lambda+\delta_{2} s\right)^{2} \\
\beta_{2}=\frac{\sqrt[3]{2}}{3 \delta_{2} \lambda}\left[12 \delta_{2} \lambda+\left(\delta_{1} s-\lambda\right)^{2}+3 s\left(\delta_{1} \lambda+\delta_{2} s\right)\right] \\
\beta_{3}=-\frac{2\left(\delta_{1} s-\lambda\right)}{3 \delta_{2} \lambda}+\frac{\left(\delta_{1} \lambda+\delta_{2} s\right)^{2}}{4 \delta_{2}^{2} \lambda^{2}} \\
\beta_{2} \lambda+\frac{4\left(\delta_{1} s-\lambda\right)\left(-\delta_{1} \lambda-\delta_{2} s\right)}{\delta_{2}^{2} \lambda^{2}}-\frac{\left(-\delta_{1} \lambda-\delta_{2} s\right)^{3}}{\delta_{2}^{3} \lambda^{3}}, \\
\beta_{5}=\beta_{1}+\sqrt{\beta_{1}^{2}-54 \delta_{2}^{2} \lambda^{2} \beta_{2}^{2}} \\
\beta_{6}=\beta_{3}+\frac{\beta_{2}}{\sqrt[3]{\beta_{5}}}+\frac{\sqrt[3]{\beta_{5}}}{\sqrt[3]{32} \delta_{2} \lambda} .
\end{gathered}
$$

3.1.4. Important Note. Solutions exist for all values of $s$ (suction and injection), $\delta_{1} \geq 0$ (first slip), and $\delta_{2} \leq 0$ (second slip). It should be noted that any number of decimal places can be therefore obtained in a direct way on applying any software package, like Mathematica, Maple, or Matlab. Mathematica 6 has been used in the current analysis, where the positive root of (19), (20), and (21) gives the physically meaningful and therefore this is only the root to be considered. In addition, Turkyilmazoglu [19] has recently proved that there exists a unique solution for any combination of the considered parameters if the stretching sheet is considered (which was also spotted in [17]). Therefore, on obtaining the roots, skin friction coefficient of the physical significance is easily given by

$$
f^{\prime \prime}(0)=\beta^{2}(s-\lambda \beta) .
$$

In an indirect and difficult analysis, this was the same result obtained by Fang et al. [18] and Nandeppanavar et al. [17], in the special case when $\lambda=1$ (i.e., when $\phi=0$ ).

3.2. Exact Solution of the Heat Transfer: $\theta(\eta)$. Substituting (18) into (16), we obtain

$$
\frac{\theta^{\prime \prime}}{\theta^{\prime}}=-\frac{1}{\tau}\left(a+b e^{-\beta \eta}\right)
$$

then by the integration of this equation, we get

$$
\theta^{\prime}(\eta)=\theta^{\prime}(0) \exp \left[-\frac{b}{\tau \beta}\left(1-e^{-\beta \eta}\right)-\frac{a}{\tau} \eta\right]
$$

Further, on integrating the last equation again, we obtain

$$
\theta(\eta)=1+\theta^{\prime}(0) e^{-(b / \tau \beta)} \Omega(\eta)
$$

where $\theta(0)=1$, and

$$
\Omega(\eta)=\int_{0}^{\eta} e^{-(a / \tau) \sigma} \times e^{(b / \tau \beta) e^{-\beta \sigma}} d \sigma .
$$

On supposing that

$$
z=-\frac{b}{\tau \beta} e^{-\beta \sigma}
$$

then (28) becomes

$$
\Omega=\frac{1}{\beta}\left(-\frac{\tau \beta}{b}\right)^{a / \tau \beta} \int_{(-b / \tau \beta) e^{-\tau \beta}}^{-b / \tau \beta} z^{(a / \tau \beta)-1} e^{-z} d z .
$$

On substituting (30) into (27), taking into account the definition of $\Gamma$ function, we obtain

$$
\theta(\eta)=1+\theta^{\prime}(0) e^{-b / \tau \beta} \frac{1}{\beta}\left(-\frac{\tau \beta}{b}\right)^{a / \tau \beta} \Gamma\left(\frac{a}{\tau \beta}, \frac{-b}{\tau \beta} e^{-\tau \beta}, \frac{-b}{\tau \beta}\right) .
$$

Applying the condition $\theta(\infty)=0$, we get

$$
\theta^{\prime}(0) e^{-b / \tau \beta} \frac{1}{\beta}\left(-\frac{\tau \beta}{b}\right)^{a / \tau \beta}=\frac{-1}{\Gamma(a / \tau \beta, 0,-b / \tau \beta)} .
$$

Hence with the help of $\Gamma$ properties, (31) is given in the final exact form as

$$
\theta(\eta)=\frac{\Gamma\left(\lambda / \tau, 0,((\lambda \beta-s) / \tau \beta) e^{-\beta \eta}\right)}{\Gamma(\lambda / \tau, 0,(\lambda \beta-s) / \tau \beta)},
$$

where $\Gamma$ here is the generalized incomplete gamma function, and $\lambda, \tau$, and $\beta$ are well defined in (17) and (19), respectively. It should be noted here that $\theta^{\prime}(0)$, which is the importance term as mentioned in Section 2, can be easily formulated from (32) and also by differentiating (33), as

$$
\theta^{\prime}(0)=-\frac{\beta e^{((s-\lambda \beta) / \tau \beta)}((\lambda \beta-s) / \tau \beta)^{(\lambda / \tau)}}{\Gamma((\lambda / \tau), 0,(\lambda \beta-s) / \tau \beta)} .
$$

\section{Results and Discussion}

In this paper, the flow and heat equations of nanofluids over an isothermal stretching sheet with effect of the slip model were analytically solved. Exact solutions were obtained for stream function, in the presence of first order and second order slips, and temperature, in a direct and very effective way using gamma function. In addition, five metallic and nonmetallic nanoparticles have been considered in this analysis, namely, Silver $(\mathrm{Ag})$, Copper $(\mathrm{Cu})$, Alumina $\left(\mathrm{Al}_{2} \mathrm{O}_{3}\right)$, Titania $\left(\mathrm{TiO}_{2}\right)$, and Silicon Dioxide $\left(\mathrm{SiO}_{2}\right)$. Comparison with the published results via four tables was presented considering the no-slip model. The two types of slip model are then considered; these cases are to be discussed in the next sections with the effect of the various physical parameters, where the Prandtl number of the base fluid (water) is kept at 6.2.

4.1. Case 1: When $\delta_{1}=\delta_{2}=0$. In the case of $\delta_{1}=\delta_{2}=$ 0 , that is, no-slip model effects, (24) and (32) with (19) have been programmed. The results of $-f^{\prime \prime}(0)$ and $-\theta^{\prime}(0)$ for variation of $\mathrm{Pr}$, different nanoparticles, and Ag-water nanoparticles are compared with Hamad [22], Wang [25], 
TABLE 2: Comparison of results for $-\theta^{\prime}(0)$ when $\phi=0, s=0$, and $\delta_{1}=\delta_{2}=0$.

\begin{tabular}{lcccc}
\hline & & & & \\
$\operatorname{Pr}$ & Present results & Hamad [22] & Wang [25] & Reddy Gorla and Sidawi [26] \\
\hline 0.07 & 0.0655625 & 0.06556 & 0.0656 & 0.0656 \\
0.02 & 0.1690886 & 0.16909 & 0.1691 & 0.1691 \\
0.70 & 0.4539162 & 0.45391 & 0.4539 & 0.4539 \\
2.00 & 0.9113577 & 0.91136 & 0.9114 & 0.9114 \\
7.00 & 1.8954033 & 1.89540 & 1.8954 & 1.8905 \\
20.0 & 3.3539041 & 3.35390 & 3.3539 & 3.3539 \\
70.0 & 6.4621995 & 6.46220 & 6.4622 & 6.4622 \\
\hline
\end{tabular}

TABLE 3: Comparison between the results of $-f^{\prime \prime}(0)$ and $-\theta^{\prime}(0)$ for different nanoparticles when $\operatorname{Pr}=6.2, s=0$, and $\delta_{1}=\delta_{2}=0$.

\begin{tabular}{|c|c|c|c|c|c|c|c|c|}
\hline \multirow{2}{*}{$\phi$} & \multicolumn{2}{|c|}{$\mathrm{Cu}$-water } & \multicolumn{2}{|c|}{ Ag-water } & \multicolumn{2}{|c|}{$\mathrm{Al}_{2} \mathrm{O}_{3}$-water } & \multicolumn{2}{|c|}{$\mathrm{TiO}_{2}$-water } \\
\hline & Present results & Hamad [22] & Present results & Hamad [22] & Present results & Hamad [22] & Present results & Hamad [22] \\
\hline \multicolumn{9}{|c|}{$-f^{\prime \prime}(0)$} \\
\hline 0.05 & 1.1089199 & 1.10892 & 1.1396597 & 1.13966 & 1.0053774 & 1.00538 & 1.0115012 & 1.01150 \\
\hline 0.10 & 1.1747460 & 1.17475 & 1.2250681 & 1.22507 & 0.9987720 & 0.99877 & 1.0095168 & 1.00952 \\
\hline 0.15 & 1.2088623 & 1.20886 & 1.2721529 & 1.27215 & 0.9818445 & 0.98185 & 0.9960305 & 0.99603 \\
\hline 0.20 & 1.2180438 & 1.21804 & 1.2897880 & 1.28979 & 0.9559188 & 0.95592 & 0.9725895 & 0.97259 \\
\hline \multicolumn{9}{|c|}{$-\theta^{\prime}(0)$} \\
\hline 0.05 & 1.5989923 & 1.59899 & 1.5813558 & 1.58136 & 1.6224626 & 1.62246 & 1.6379138 & 1.63791 \\
\hline 0.10 & 1.4520723 & 1.45207 & 1.4205773 & 1.42058 & 1.4916979 & 1.49170 & 1.5195895 & 1.51959 \\
\hline 0.15 & 1.3246459 & 1.32465 & 1.2819255 & 1.28193 & 1.3754278 & 1.37543 & 1.4135927 & 1.41359 \\
\hline 0.20 & 1.2128974 & 1.21290 & 1.1609900 & 1.16100 & 1.2711811 & 1.27118 & 1.3180499 & 1.31805 \\
\hline
\end{tabular}

TABLE 4: Comparison between the results of $-f^{\prime \prime}(0)$ and $-\theta^{\prime}(0)$ for Ag-water nanoparticles when $\operatorname{Pr}=6.2$ and $\delta_{1}=\delta_{2}=0$.

\begin{tabular}{|c|c|c|c|c|c|c|c|c|}
\hline \multirow{2}{*}{$\phi$} & \multicolumn{2}{|c|}{$s=-0.5$} & \multicolumn{2}{|c|}{$s=0.5$} & \multicolumn{2}{|c|}{$s=3$} & \multicolumn{2}{|c|}{$s=10$} \\
\hline & Present results & $\begin{array}{l}\text { Noghrehabadi } \\
\text { et al. [23] }\end{array}$ & Present results & $\begin{array}{l}\text { Noghrehabadi } \\
\text { et al. [23] }\end{array}$ & Present results & $\begin{array}{l}\text { Noghrehabadi } \\
\text { et al. [23] }\end{array}$ & Present results & $\begin{array}{c}\text { Noghrehabadi } \\
\text { et al. [23] }\end{array}$ \\
\hline \multicolumn{9}{|c|}{$-f^{\prime \prime}(0)$} \\
\hline 0.00 & 0.7807764 & 0.78078 & 1.2807764 & 1.28078 & 3.3027756 & 3.30278 & 10.099020 & 10.09902 \\
\hline 0.05 & 0.8603080 & 0.86031 & 1.5097201 & 1.50972 & 4.2053250 & 4.20532 & 13.087484 & 13.08748 \\
\hline 0.10 & 0.9060379 & 0.90604 & 1.6564339 & 1.65643 & 4.8141236 & 4.81412 & 15.107262 & 15.10726 \\
\hline 0.15 & 0.9303482 & 0.93035 & 1.7395348 & 1.73953 & 5.1682565 & 5.16826 & 16.283121 & 16.28312 \\
\hline 0.20 & 0.9392930 & 0.93929 & 1.7710695 & 1.77107 & 5.3042838 & 5.30428 & 16.734937 & 16.73494 \\
\hline \multicolumn{9}{|c|}{$-\theta^{\prime}(0)$} \\
\hline 0.00 & 0.3341463 & 0.33415 & 4.1338760 & 4.13375 & 18.877000 & 18.87699 & 62.085783 & 62.08581 \\
\hline 0.05 & 0.3374948 & 0.33750 & 3.5686858 & 3.56861 & 16.003319 & 16.00329 & 52.565657 & 52.56564 \\
\hline 0.10 & 0.3412474 & 0.34125 & 3.0990601 & 3.00902 & 13.637179 & 13.63716 & 44.731160 & 44.73115 \\
\hline 0.15 & 0.3441451 & 0.34415 & 2.7036778 & 2.70365 & 11.662391 & 11.66238 & 38.194788 & 38.19476 \\
\hline 0.20 & 0.3458192 & 0.34582 & 2.3673248 & 2.36732 & 9.995764 & 9.99572 & 32.679360 & 32.67934 \\
\hline
\end{tabular}

Reddy Gorla and Sidawi [26], and Noghrehabadi et al. [23] in Tables 2, 3, and 4, respectively. These tables indicate an excellent agreement between the present exact solutions and the previous results but in a simple and direct analysis rather than the long analytical presentation in [22] and even the difficult combination of a symbolic power series and Padé approximation method in [23].
4.2. Case 2: When $\delta_{1} \neq 0$ and $\delta_{2}=0$. Figures 1 and 2 show the effect of the volume friction $\phi$ of $\mathrm{Cu}$-water and $\mathrm{Al}_{2} \mathrm{O}_{3}$-water nanoparticles, respectively, on velocity distribution $f^{\prime}(\eta)$ at different values of $s$ when $\operatorname{Pr}=6.2$ and $\delta_{1}=1$. These figures indicate that the increase in nanoparticle volume friction decreases the velocity magnitude in the case of $\mathrm{Cu}$-water nanofluid; however it increases the velocity magnitude in 


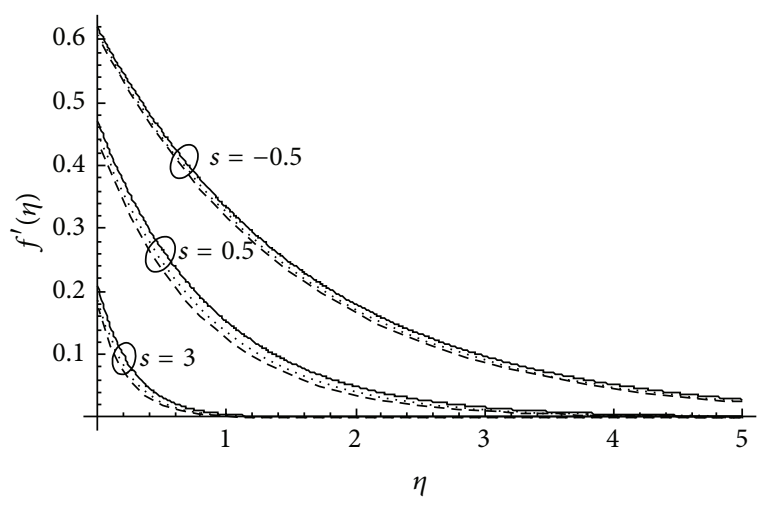

Cu-water
$-\phi=0.05$
$\ldots \ldots=0.1$

FIGURE 1: Effect of the volume friction $\phi$ of $\mathrm{Cu}$-water nanoparticles on velocity distribution $f^{\prime}(\eta)$ at different values of $s$ when $\operatorname{Pr}=6.2$, $\delta_{1}=1$, and $\delta_{2}=0$.

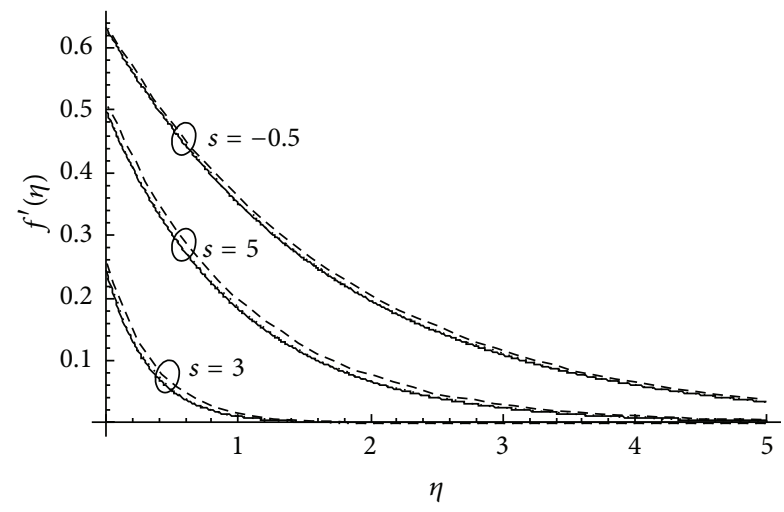

$$
\begin{aligned}
& \mathrm{Al}_{2} \mathrm{O}_{3} \text {-water } \\
& -\phi=0.05 \\
& \cdots \ldots=0.1
\end{aligned}
$$

FIgURE 2: Effect of the volume friction $\phi$ of $\mathrm{Al}_{2} \mathrm{O}_{3}$-water nanoparticles on velocity distribution $f^{\prime}(\eta)$ at different values of $s$ when $\operatorname{Pr}=6.2, \delta_{1}=1$, and $\delta_{2}=0$.

the case of $\mathrm{Al}_{2} \mathrm{O}_{3}$-water nanofluid. The difference between their behaviour is because of the difference between density ratios of the proposed nanoparticles to the density of water, which affects the momentum equation. Further, in both cases of $\mathrm{Cu}$-water and $\mathrm{Al}_{2} \mathrm{O}_{3}$-water nanofluids, the increase in $s$ decreases the magnitude of $f^{\prime}(\eta)$ and hydrodynamic boundary layer. It should be mentioned here that the other nanoparticles have been also examined and it was found that $\mathrm{Ag}$-water nanofluid behaves like $\mathrm{Cu}$-water nanofluid, while $\mathrm{TiO}_{2}$-water and $\mathrm{SiO}_{2}$-water nanofluids behave as $\mathrm{Al}_{2} \mathrm{O}_{3}$ water nanofluid. However, the velocity distribution $f^{\prime}(\eta)$ of these nanoparticles is as follows: $\left.f^{\prime}\right|_{\mathrm{Ag}}<\left.f^{\prime}\right|_{\mathrm{Cu}}<\left.f^{\prime}\right|_{\mathrm{TiO}_{2}}<$ $\left.\left.f^{\prime}\right|_{\mathrm{Al}_{2} \mathrm{O}_{3}} \cong f^{\prime}\right|_{\mathrm{SiO}_{2}}$. This is presented in Figure 3, which shows a comparison of the variation of the velocity profiles for all

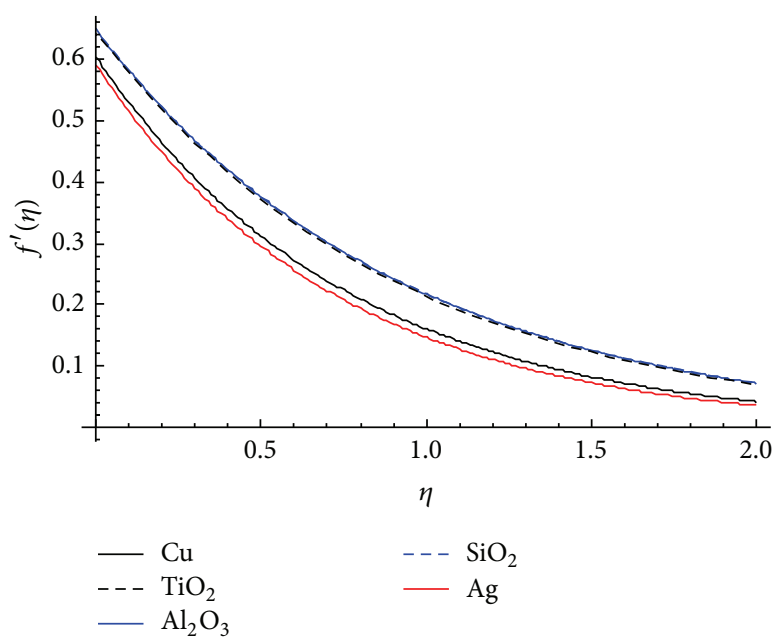

FIGURE 3: Comparing the variation of velocity distribution $f^{\prime}(\eta)$ for the investigated nanoparticles when $\operatorname{Pr}=6.2, \delta_{1}=0.5, \delta_{2}=0$, $s=0.5$, and $\phi=0.1$.

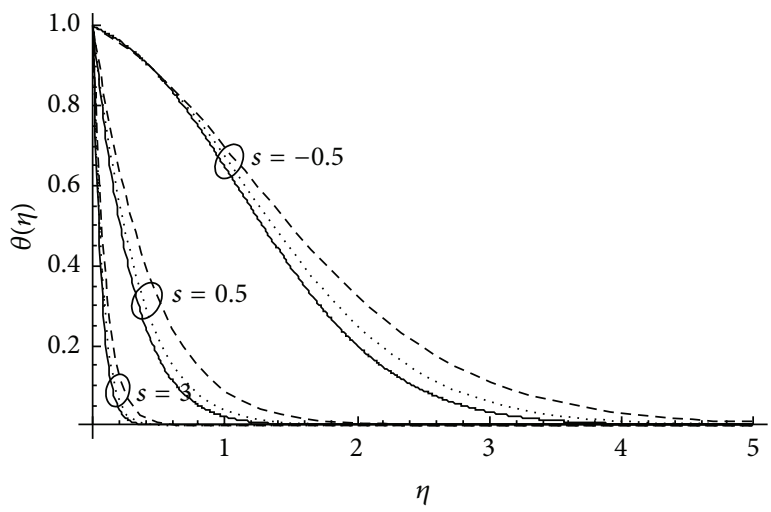

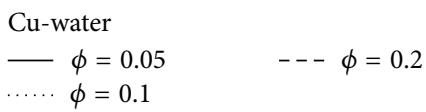

FIGURE 4: Effect of the volume friction $\phi$ of $\mathrm{Cu}$-water nanoparticles on temperature distribution $\theta(\eta)$ at different values of $s$ when $\operatorname{Pr}=$ $6.2, \delta_{1}=1$, and $\delta_{2}=0$.

the studied nanoparticles at specific values of the physical parameters.

The effect of the volume friction $\phi$ of $\mathrm{Cu}$-water nanoparticles on temperature distribution $\theta(\eta)$ at different values of $s$ when $\operatorname{Pr}=6.2$ and $\delta_{1}=1$ is plotted in Figure 4. This figure indicates that the increase in $\phi$ increases $\theta(\eta)$ and hence the thermal boundary-layer thickness. This result is compatible with those obtained very recently by Vajravelu et al. [24] and also agrees with the physical behaviour as addition of $\phi$ increases the thermal conductivity of the pure fluid and this results in increasing the thermal diffusion in the boundary layer. Further, increase in $s$ decreases $\theta(\eta)$ as well as the thermal boundary-layer thickness. All of the other investigated nanoparticles behave like $\mathrm{Cu}$-water nanofluid with $\left.\theta\right|_{\mathrm{Ag}}>\left.\theta\right|_{\mathrm{Cu}}>\left.\left.\theta\right|_{\mathrm{Al}_{2} \mathrm{O}_{3}} \cong \theta\right|_{\mathrm{SiO}_{2}}>\left.\theta\right|_{\mathrm{TiO}_{2}}$, as illustrated 


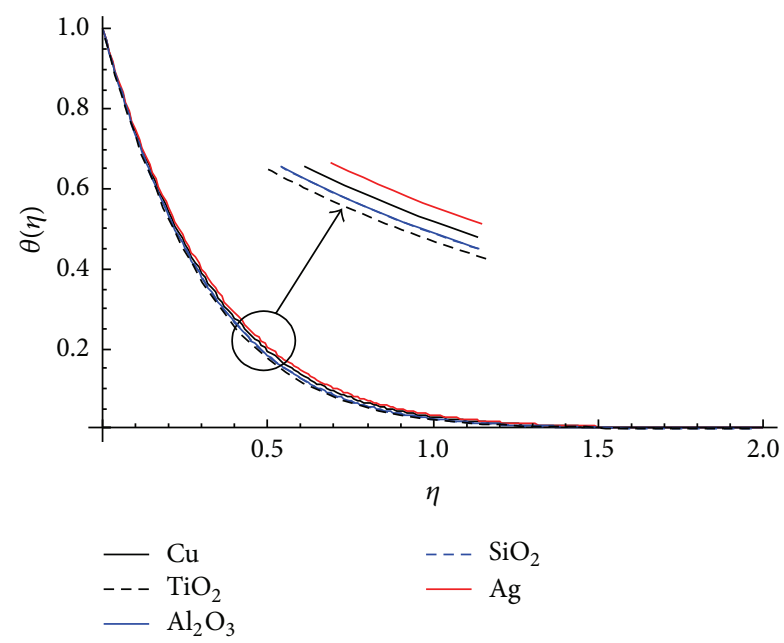

Figure 5: Comparing the variation of temperature distribution $\theta(\eta)$ for the investigated nanoparticles when $\operatorname{Pr}=6.2, \delta_{1}=0.5, \delta_{2}=0$, $s=0.5$, and $\phi=0.1$.

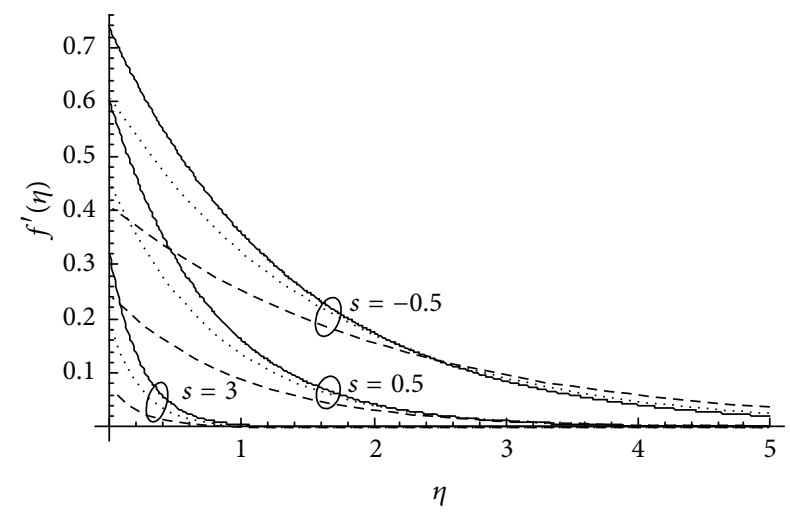

$$
\begin{aligned}
& \text { Cu-water } \\
& -\delta_{1}=0.5 \\
& \ldots \ldots \delta_{1}=1
\end{aligned}
$$

FIGURE 6: Effect of the first slip $\delta_{1}$ on velocity distribution $f^{\prime}(\eta)$ at different values of $s$ for $\mathrm{Cu}$-water nanoparticles when $\operatorname{Pr}=6.2, \phi=$ 0.1 , and $\delta_{2}=0$.

in Figure 5, which presents a comparison of the variation of temperature distribution for all the studied nanoparticles at specific values of the physical parameters.

Figures 6 and 7 present the effect of the first slip $\delta_{1}$ on the velocity $f^{\prime}$ and temperature $\theta$ distributions at different values of $s$ for $\mathrm{Cu}$-water nanoparticles when $\operatorname{Pr}=6.2$, and $\phi=0.1$, respectively. Figure 6 shows that the increase in $\delta_{1}$ significantly decreases the velocity near $\eta=0$ and then slightly increases it as $\eta \rightarrow \eta_{\infty}$. However, the increase in $\delta_{1}$ increases significantly the temperature and thermal boundary-layer thickness in the injection case, that is, when $s<0$, with a little increasing in the suction case when $s>0$, and no effect when $s \gg 1$. From these figures, one can also notice that increase in $s$ decreases $f^{\prime}(\eta)$ and $\theta(\eta)$, as well as the hydrodynamic and thermal boundary-layer thickness, respectively. This means that, although the increase in the first

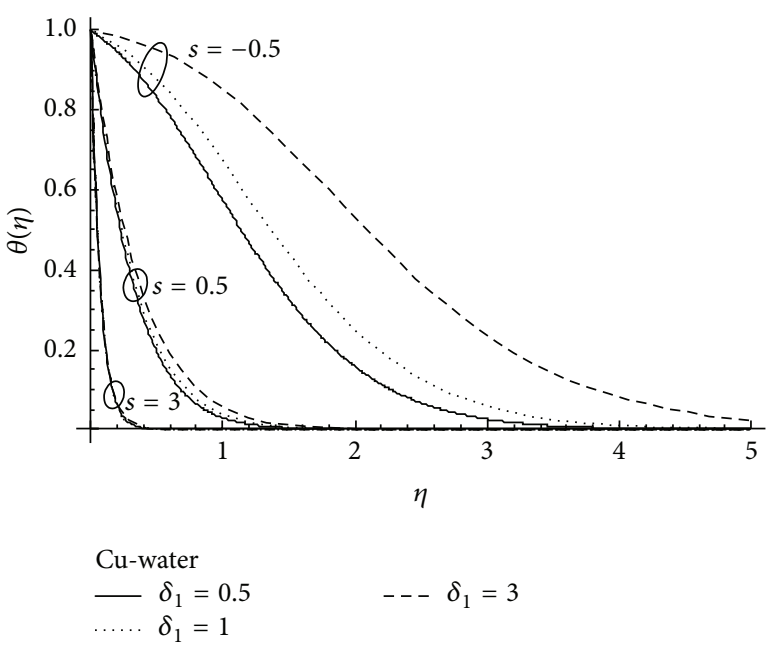

FIGURE 7: Effect of the first slip $\delta_{1}$ on temperature distribution $\theta(\eta)$ at different values of $s$ for $\mathrm{Cu}$-water nanoparticles when $\operatorname{Pr}=6.2$, $\phi=0.1$, and $\delta_{2}=0$.

slip slows down the velocity, it increases the temperature with impressive effect in the injection case.

The most important parameters of hydrodynamic and thermal boundary layer, namely, reduced skin friction coefficient and reduced Nusselt number, have been indicated in Figures 8-11. In particular, Figures 8 and 9 present the effect of the first slip $\delta_{1}$ and $s$, respectively, for reduced skin friction coefficient as a function of $0 \leq \phi \leq 0.2$ for $\mathrm{Cu}-$ water nanofluid, as a representative for the behaviour of all investigated nanoparticles, when $\operatorname{Pr}=6.2$ and $s=0.5$, while Figures 10 and 11 show also the effect of $\delta_{1}$ and $s$ on reduced Nusselt number at the same specific values. Figures 8 and 9 show that increase in $\delta_{1}$ and $s$ decreases and increases, respectively, the local skin friction. With significant effects, the same result is also observed in Figures 10 and 11 for the reduced Nusselt number.

Comparison of the variation of reduced skin friction coefficient and reduced Nusselt number for the studied nanoparticles, at selected values of the physical parameters, is plotted in Figures 12 and 13. These figures show that the reduced skin friction coefficient (RSFC) of these nanoparticles is as follows: $\mathrm{RSFCl}_{\mathrm{Ag}}>\mathrm{RSFCl}_{\mathrm{Cu}}>\mathrm{RSFCl}_{\mathrm{TiO}_{2}}>\mathrm{RSFCl}_{\mathrm{Al}_{2} \mathrm{O}_{3}}$ $\left.\cong \mathrm{RSFC}\right|_{\mathrm{SiO}_{2}}$. However, vise versa behaviour is noticed in Figure 13. The difference between these types of nanoparticles is because the difference between their densities. Observing Table 1 and (15)-(17), as the nanoparticle becomes heavy, this results in increase and decrease in reduced skin friction coefficient and reduced Nusselt number, respectively.

4.3. Case 3: When $\delta_{1} \neq 0$, and $\delta_{2} \neq 0$. In the presence of second order slip, as shown in Figures 14, 15, 16, and 17, behaviour of the velocity and temperature is similar to those in 1, 3, 4, and 5, respectively. However, for Ag-water and $\mathrm{Cu}$-water nanoparticles, a decreasing difference is noticed on comparing Figures 15 and 3. This means that the second slip affects significantly the heaviest nanoparticles. Figures 18 and 


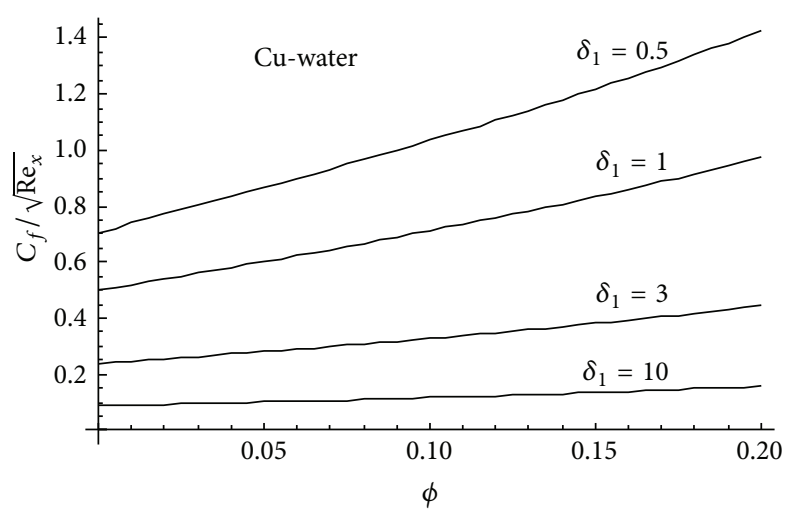

FIGURE 8: Effect of the first slip $\delta_{1}$ on reduced skin friction coefficient as a function of $0 \leq \phi \leq 0.2$ for Cu-water nanoparticles when $P r=6.2$, $s=0.5$, and $\delta_{2}=0$.

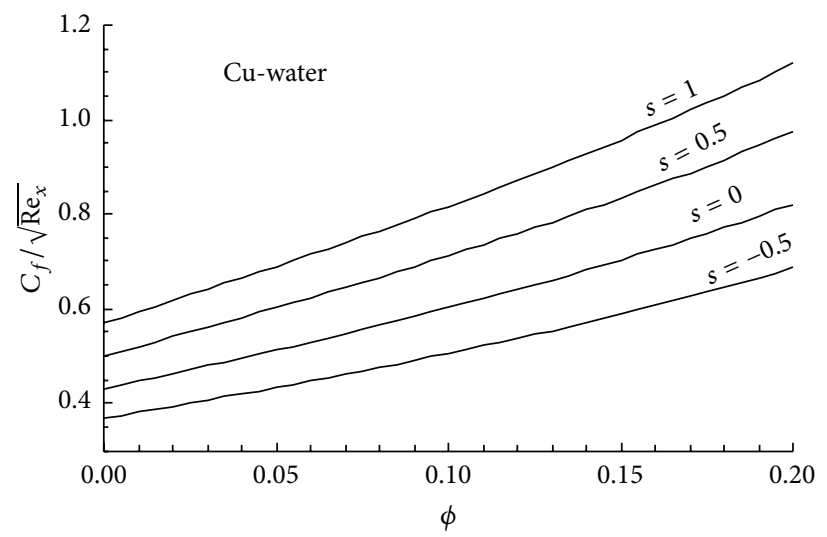

FIGURE 9: Effect of $s$ on reduced skin friction coefficient as a function of $0 \leq \phi \leq 0.2$ for Cu-water nanoparticles when $\operatorname{Pr}=6.2, \delta_{1}=1$, and $\delta_{2}=0$.

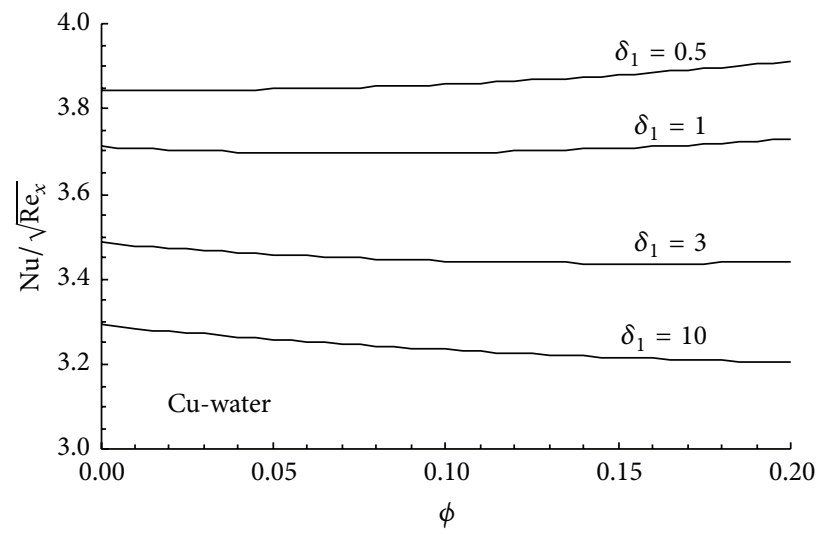

FIgURE 10: Effect of the first slip $\delta_{1}$ on reduced Nusselt number as a function of $0 \leq \phi \leq 0.2$ for Cu-water nanoparticles when $\mathrm{Pr}=6.2$, $s=0.5$, and $\delta_{2}=0$.

19 compare the variation of reduced skin friction coefficient and reduced Nusselt number, respectively, for the studied nanoparticles, at selected values of the physical parameters. These figures show that the RSFC of these nanoparticles is as follows: $\left.\mathrm{RSFC|}\right|_{\mathrm{Ag}}<\mathrm{RSFCl}_{\mathrm{Cu}}<\left.\mathrm{RSFC}\right|_{\mathrm{TiO}_{2}}<\mathrm{RSFC}_{\mathrm{Al}_{2} \mathrm{O}_{3}} \cong$ RSFC| $\left.\right|_{\mathrm{SiO}_{2}}$. This is vise versa behaviour comparing with
Figure 12 with significant change in the $\mathrm{Ag}$-water and $\mathrm{Cu}$ water nanoparticles, as stated before. Although the same behaviour is observed in Figures 13 and 19, the nanoparticles with highest density are more affected in the presence of the second slip. The results of this section demonstrate clearly that the second order slip flow model is necessary to predict 


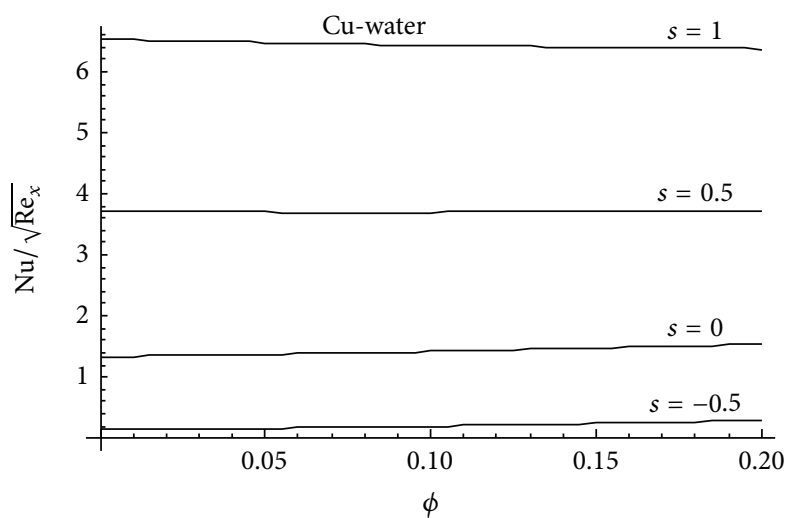

Figure 11: Effect of $s$ on reduced Nusselt number as a function of $0 \leq \phi \leq 0.2$ for Cu nanoparticles when $\operatorname{Pr}=6.2, \delta_{1}=1$, and $\delta_{2}=0$.

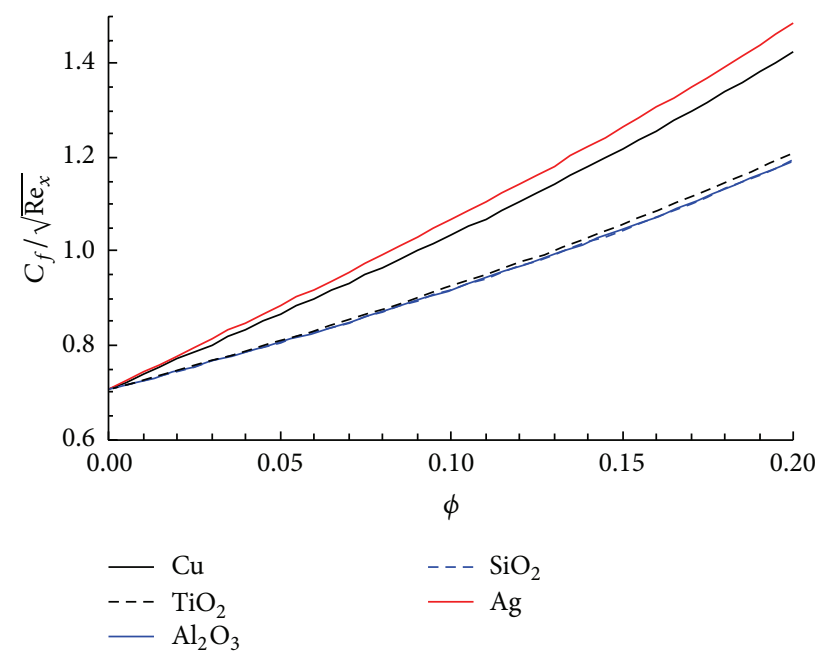

FIGURE 12: Comparing the variation of reduced skin friction coefficient as a function of $0 \leq \phi \leq 0.2$ for the investigated nanoparticles $P r=6.2$, $\delta_{1}=0.5, \delta_{2}=0$, and $s=0.5$.

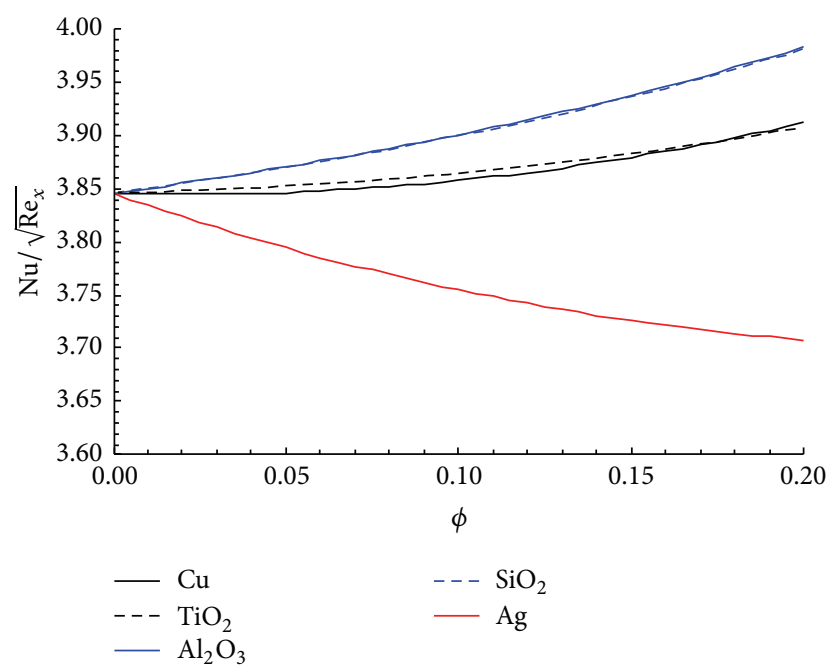

FIGURE 13: Comparing the variation of reduced Nusselt number as a function of $0 \leq \phi \leq 0.2$ for the investigated nanoparticles $\operatorname{Pr}=6.2$, $\delta_{1}=0.5, \delta_{2}=0$, and $s=0.5$. 


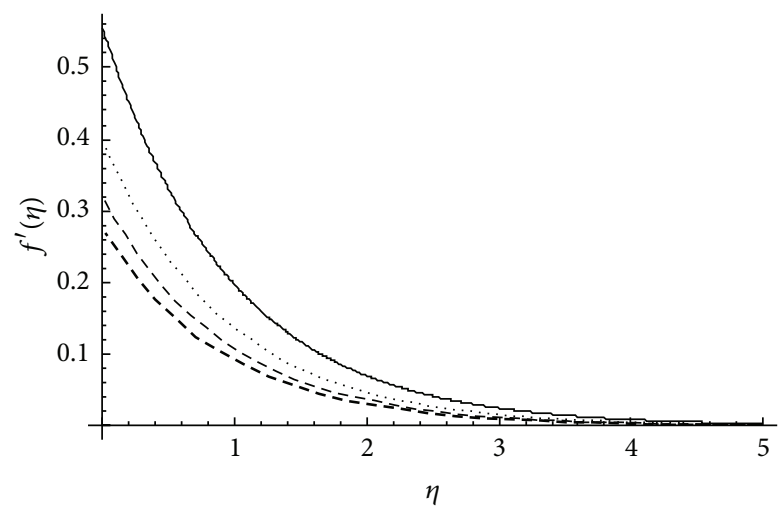

Cu-water

$\begin{aligned} \phi & =0 & --\phi & =0.1 \\ \ldots \ldots \phi & =0.05 & ---\phi & =0.2\end{aligned}$

FIGURE 14: Effect of the volume friction $\phi$ of Cu-water nanoparticles on velocity distribution $f^{\prime}(\eta)$ when $\operatorname{Pr}=6.2, s=0.5, \delta_{1}=1$, and $\delta_{2}=-1$.

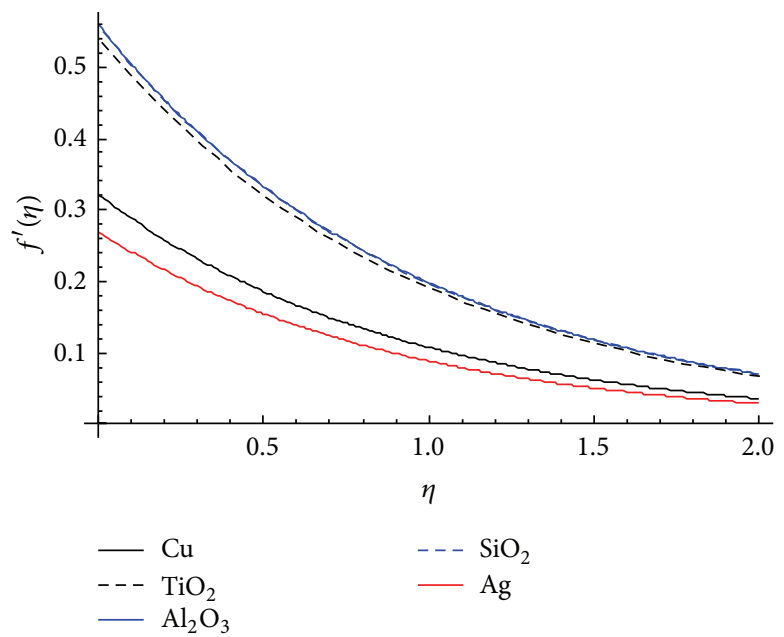

Figure 15: Comparing the variation of velocity distribution $f^{\prime}(\eta)$ for the investigated nanoparticles when $\operatorname{Pr}=6.2, \delta_{1}=1, \delta_{2}=-1, s=0.5$, and $\phi=0.1$.
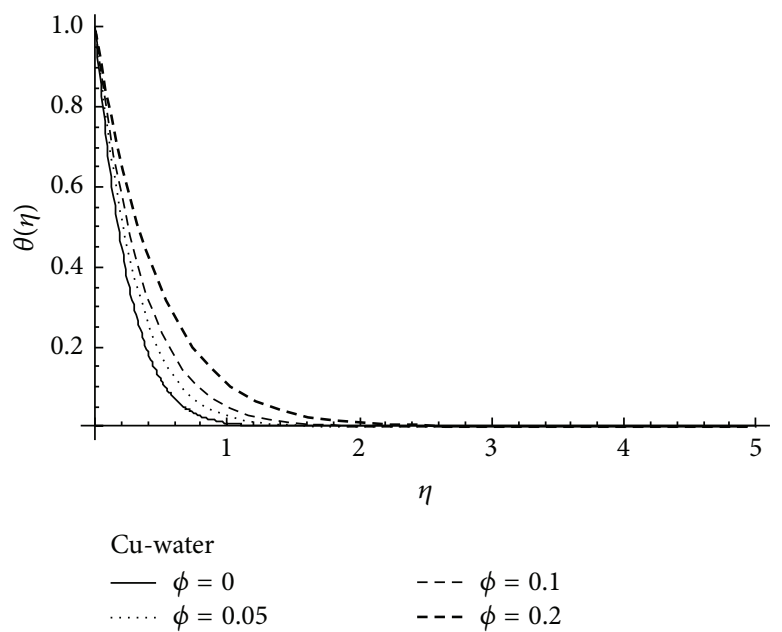

FiguRE 16: Effect of the volume friction $\phi$ of Cu-water nanoparticles on temperature distribution $\theta(\eta)$ when $\operatorname{Pr}=6.2, s=0.5, \delta_{1}=1$, and $\delta_{2}=-1$. 


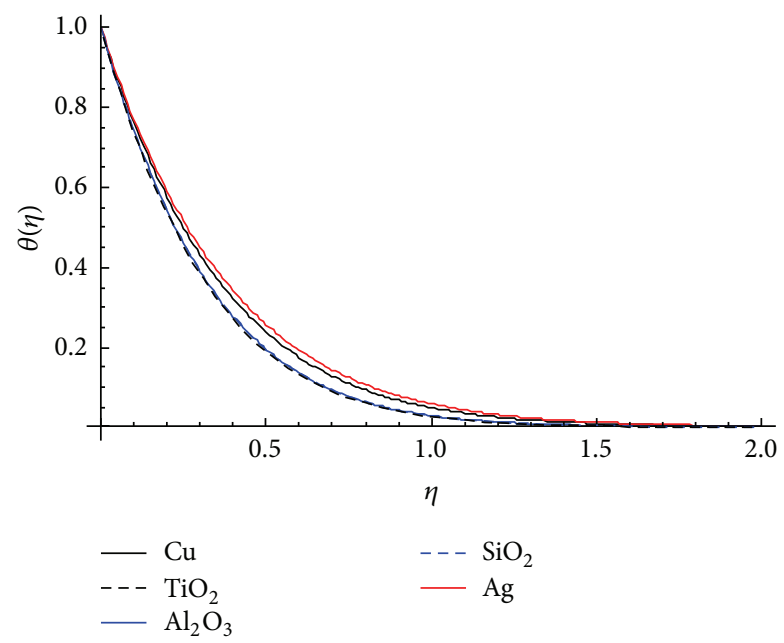

FIgURE 17: Comparing the variation of temperature distribution $\theta(\eta)$ for the investigated nanoparticles when $\operatorname{Pr}=6.2, \delta_{1}=1, \delta_{2}=-1$, $s=0.5$, and $\phi=0.1$.

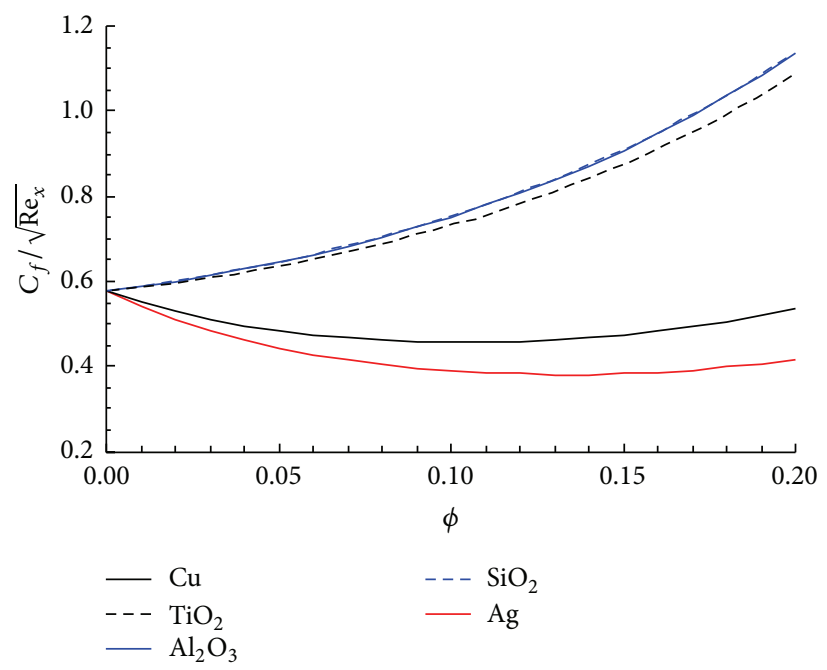

FIGURE 18: Comparing the variation of reduced skin friction coefficient as a function of $0 \leq \phi \leq 0.2$ for the investigated nanoparticles $P r=6.2$, $\delta_{1}=1, \delta_{2}=-1$, and $s=0.5$.

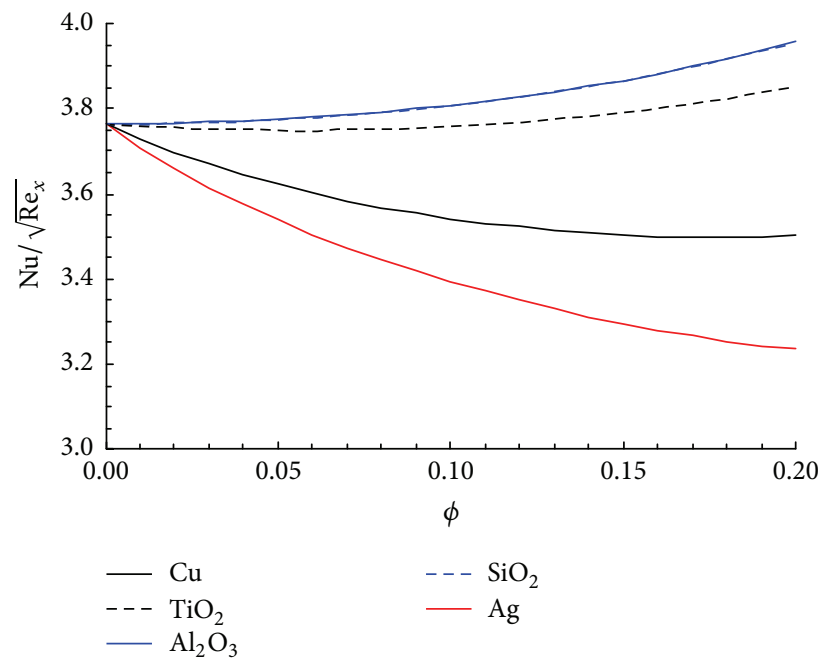

FIGURE 19: Comparing the variation of reduced Nusselt number as a function of $0 \leq \phi \leq 0.2$ for the investigated nanoparticles $\mathrm{Pr}=6.2$, $\delta_{1}=1, \delta_{2}=-1$, and $s=0.5$. 
the flow characteristics accurately. This agrees with the result obtained recently by Roşca and Pop [20].

\section{Conclusion}

The governing equations for nanofluids flow over an isothermal stretching sheet with the effect of the slip model were examined in this paper. In a direct and very effective manner, we analytically obtained the exact solutions for the flow and temperature equations. Further, five nanoparticles were considered and compared in the present analysis. Therefore, the most interesting physical parameters were discussed in the presence of no slip, first order slip, and second order slip, parameters.

With no-slip effect, the present exact solutions are in a very good agreement with the results presented in $[22,23,25$, 26]. Some of the interesting results of applying the slip model are as follows:

(1) increase in the nanoparticle volume friction decreases the velocity of $\mathrm{Cu} / \mathrm{Ag}$-water nanoparticles, increases it for $\mathrm{Al}_{2} \mathrm{O}_{3} / \mathrm{TiO}_{2} / \mathrm{SiO}_{2}$-water nanoparticles, and increases the temperature, and hence the thermal boundary-layer thickness, for the whole five investigated nanoparticles;

(2) increase in the wall mass decreases the velocity and temperature, as well as the thermal and hydrodynamic boundary-layer thickness, and increases the local skin friction;

(3) increase in the slips slows down the velocity, increases the temperature with an impressive effect in the injection case, and decreases the local skin friction and the reduced Nusselt number, with significate effects;

(4) as the nanoparticle becomes heavier, this results in increase and decrease in the reduced skin friction coefficient and reduced Nusselt number, respectively;

(5) the second order slip parameter affects considerably the flow characteristics, specially for the heaviest nanoparticles.

The final note is for practical and industrial applications; Silver is the suitable nanoparticle if slowing down the velocity and increasing the temperature are needed; on the other hand, Silicon Dioxide is the appropriate nanoparticle if vise versa behaviour is to be considered.

\section{Conflict of Interests}

The authors declare that there is no conflict of interests regarding the publication of this paper.

\section{Acknowledgment}

This paper was funded by the Deanship of Scientific Research (DSR), King Abdulaziz University, Jeddah, under grant no. (130-011-D1433). The authors, therefore, acknowledge with thanks DSR technical and financial support.

\section{References}

[1] T. Metal, S. Oh, and H. Gegel, Metal Forming Fundamentals and Applications, American Society of Metals, Metals Park, Ohio, USA, 1979.

[2] M. V. Karwe and Y. Jaluria, "Numerical simulation of thermal transport associated with a continuously moving flat sheet in materials processing," Journal of Heat Transfer, vol. 113, no. 3, pp. 612-619, 1991.

[3] B. C. Sakiadis, "Boundary layer behaviour on continuous solid surfaces-I. Boundary layer equations for two-dimensional and axisymmetric flow," AIChE Journal, vol. 7, pp. 26-28, 1961.

[4] B. C. Sakiadis, "Boundary layer behaviour on continuous solid surfaces-II. The boundary layer on a continuous flat surface," AIChE Journal, vol. 7, pp. 221-225, 1961.

[5] L. J. Crane, "Flow past a stretching plate," Zeitschrift für Angewandte Mathematik und Physik, vol. 21, no. 4, pp. 645-647, 1970.

[6] A. Yoshimura and R. K. Prud'homme, "Wall slip corrections for Couette and parallel disk viscometers," Journal of Rheology, vol. 32, no. 1, pp. 53-67, 1988.

[7] M. Gad-el-Hak, "Fluid mechanics of microdevices-the freeman scholar lecture," Journal of Fluids Engineering, Transactions of the ASME, vol. 121, no. 1, pp. 5-33, 1999.

[8] X.-Q. Wang and A. S. Mujumdar, "Heat transfer characteristics of nanofluids: a review," International Journal of Thermal Sciences, vol. 46, no. 1, pp. 1-19, 2007.

[9] X.-Q. Wang and A. S. Mujumdar, "A review on nanofluids-part II: experiments and applications," Brazilian Journal of Chemical Engineering, vol. 25, no. 4, pp. 631-648, 2008.

[10] R. Saidur, K. Y. Leong, and H. A. Mohammad, "A review on applications and challenges of nanofluids," Renewable and Sustainable Energy Reviews, vol. 15, no. 3, pp. 1646-1668, 2011.

[11] S. U. S. Choi, "Enhancing thermal conductivity of fluids with nanoparticles," Developments and Applications of NonNewtonian Flows, vol. 66, pp. 99-105, 1995.

[12] J. A. Eastman, S. U. S. Choi, S. Li, W. Yu, and L. J. Thompson, "Anomalously increased effective thermal conductivities of ethylene glycol-based nanofluids containing copper nanoparticles," Applied Physics Letters, vol. 78, no. 6, pp. 718-720, 2001.

[13] Y. Xuan and Q. Li, "Investigation on convective heat transfer and flow features of nanofluids," Journal of Heat Transfer, vol. 125, no. 1, pp. 151-155, 2003.

[14] M. Majumder, N. Chopra, R. Andrews, and B. J. Hinds, "Nanoscale hydrodynamics: enhanced flow in carbon nanotubes," Nature, vol. 438, no. 7064, article 44, 2005.

[15] A. Noghrehabadi, R. Pourrajab, and M. Ghalambaz, "Effect of partial slip boundary condition on the flow and heat transfer of nanofluids past stretching sheet prescribed constant wall temperature," International Journal of Thermal Sciences, vol. 54, pp. 253-261, 2012.

[16] W. A. Khan and I. Pop, "Boundary-layer flow of a nanofluid past a stretching sheet," International Journal of Heat and Mass Transfer, vol. 53, no. 11-12, pp. 2477-2483, 2010.

[17] M. M. Nandeppanavar, K. Vajravelu, M. S. Abel, and M. N. Siddalingappa, "Second order slip flow and heat transfer over a stretching sheet with non-linear Navier boundary condition," International Journal of Thermal Sciences, vol. 58, pp. 143-150, 2012. 
[18] T. Fang, S. Yao, J. Zhang, and A. Aziz, "Viscous flow over a shrinking sheet with a second order slip flow model," Communications in Nonlinear Science and Numerical Simulation, vol. 15, no. 7, pp. 1831-1842, 2010.

[19] M. Turkyilmazoglu, "Heat and mass transfer of MHD second order slip flow," Computers \& Fluids, vol. 71, pp. 426-434, 2013.

[20] A. V. Roşca and I. Pop, "Flow and heat transfer over a vertical permeable stretching/shrinking sheet with a second order slip," International Journal of Heat and Mass Transfer, vol. 60, pp. 355364, 2013.

[21] N. A. Yacob, A. Ishak, I. Pop, and K. Vajravelu, "Boundary layer flow past a stretching/shrinking surface beneath an external uniform shear flow with a convective surface boundary condition in a nanofluid," Nanoscale Research Letters, vol. 6, pp. 314321, 2011.

[22] M. A. A. Hamad, "Analytical solution of natural convection flow of a nanofluid over a linearly stretching sheet in the presence of magnetic field," International Communications in Heat and Mass Transfer, vol. 38, no. 4, pp. 487-492, 2011.

[23] A. Noghrehabadi, M. Ghalambaz, M. Ghalambaz, and A. Ghanbarzadeh, "Comparing thermal enhancement of Ag-water and $\mathrm{SiO}_{2}$-water nanofluids over an isothermal stretching sheet with suction or injection," Journal of Computational and Applied Research in Mechanical Engineering, vol. 2, pp. 35-47, 2012.

[24] K. Vajravelu, K. V. Prasad, and C.-O. Ng, “The effect of variable viscosity on the flow and heat transfer of a viscous Ag-water and $\mathrm{Cu}$-water nanofluids," Journal of Hydrodynamics, vol. 25, pp. 19, 2013.

[25] C. Y. Wang, "Free convection on a vertical stretching surface," Journal of Applied Mathematics and Mechanics, vol. 69, pp. 418420, 1989.

[26] R. S. Reddy Gorla and I. Sidawi, "Free convection on a vertical stretching surface with suction and blowing," Applied Scientific Research, vol. 52, no. 3, pp. 247-257, 1994.

[27] H. F. Oztop and E. Abu-Nada, "Numerical study of natural convection in partially heated rectangular enclosures filled with nanofluids," International Journal of Heat and Fluid Flow, vol. 29, no. 5, pp. 1326-1336, 2008.

[28] K. Khanafer, K. Vafai, and M. Lightstone, "Buoyancy-driven heat transfer enhancement in a two-dimensional enclosure utilizing nanofluids," International Journal of Heat and Mass Transfer, vol. 46, no. 19, pp. 3639-3653, 2003.

[29] K. Khanafer and K. Vafai, "A critical synthesis of thermophysical characteristics of nanofluids," International Journal of Heat and Mass Transfer, vol. 54, no. 19-20, pp. 4410-4428, 2011.

[30] L. Wu, "A slip model for rarefied gas flows at arbitrary Knudsen number," Applied Physics Letters, vol. 93, no. 25, Article ID 253103, 2008.

[31] K. Vajravelu, K. V. Prasad, J. Lee, C. Lee, I. Pop, and R. A. Van Gorder, "Convective heat transfer in the flow of viscous Ag-water and $\mathrm{Cu}$-water nanofluids over a stretching surface," International Journal of Thermal Sciences, vol. 50, no. 5, pp. 843851, 2011.

[32] C. Y. Wang, "Analysis of viscous flow due to a stretching sheet with surface slip and suction," Nonlinear Analysis. Real World Applications, vol. 10, no. 1, pp. 375-380, 2009.

[33] E. H. Aly and A. Ebaid, "On the exact analytical and numerical solutions of nano boundary-layer fluid flows," Abstract and Applied Analysis, vol. 2012, Article ID 415431, 22 pages, 2012.

[34] E. H. Aly and A. Ebaid, "New exact solutions for boundarylayer flow of a nanofluid past a stretching sheet," Journal of
Computational and Theoretical Nanoscience, vol. 10, pp. 25912595, 2013.

[35] R. A. Van Gorder, E. Sweet, and K. Vajravelu, "Nano boundary layers over stretching surfaces," Communications in Nonlinear Science and Numerical Simulation, vol. 15, no. 6, pp. 1494-1500, 2010. 


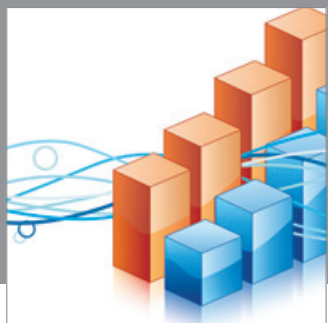

Advances in

Operations Research

mansans

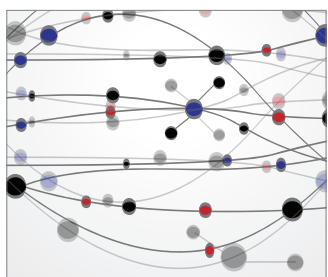

The Scientific World Journal
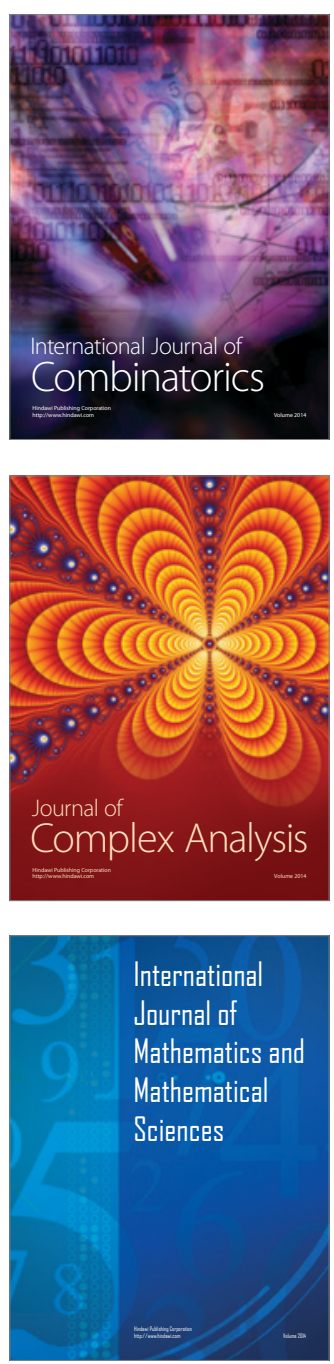
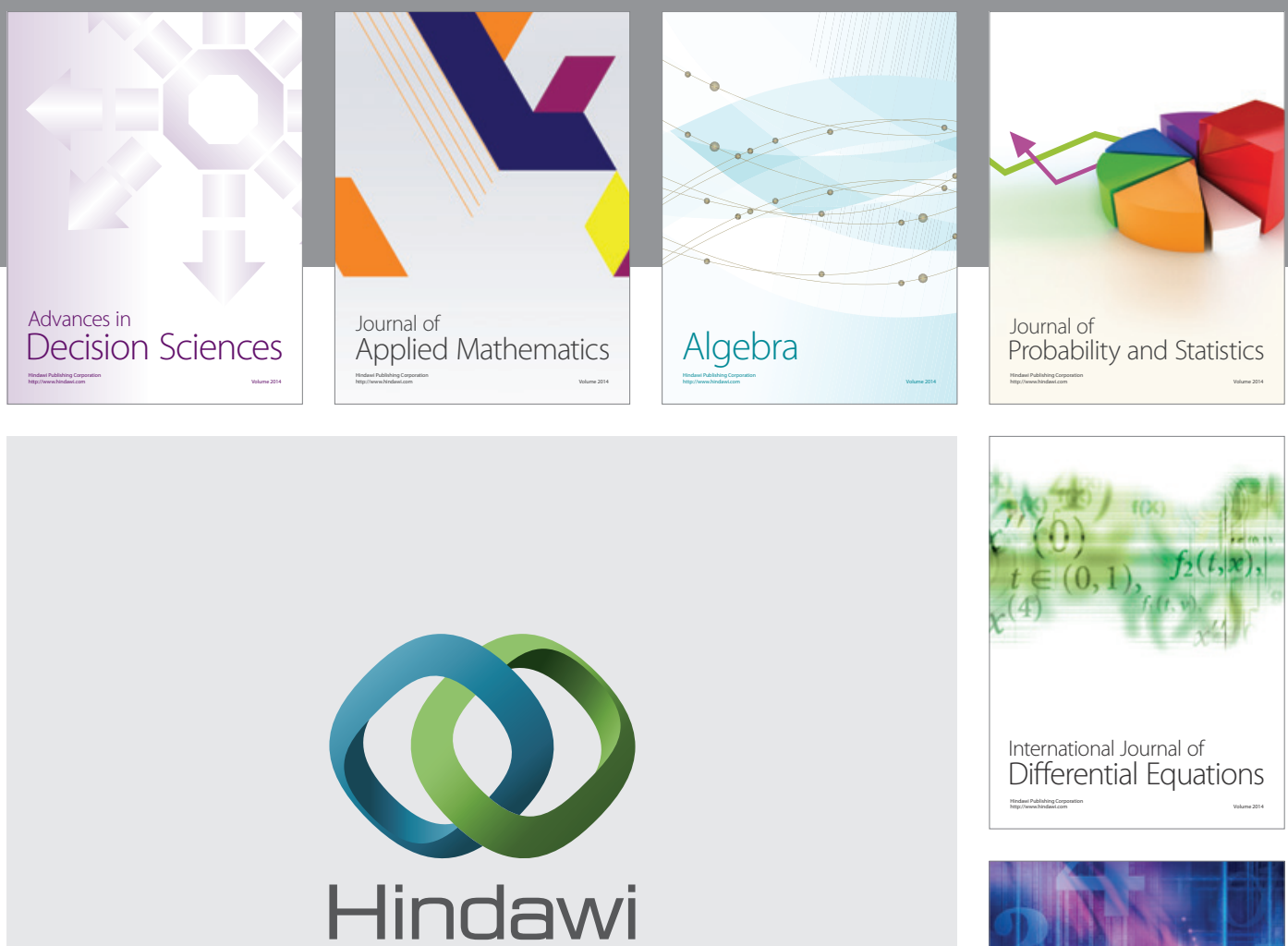

Submit your manuscripts at http://www.hindawi.com
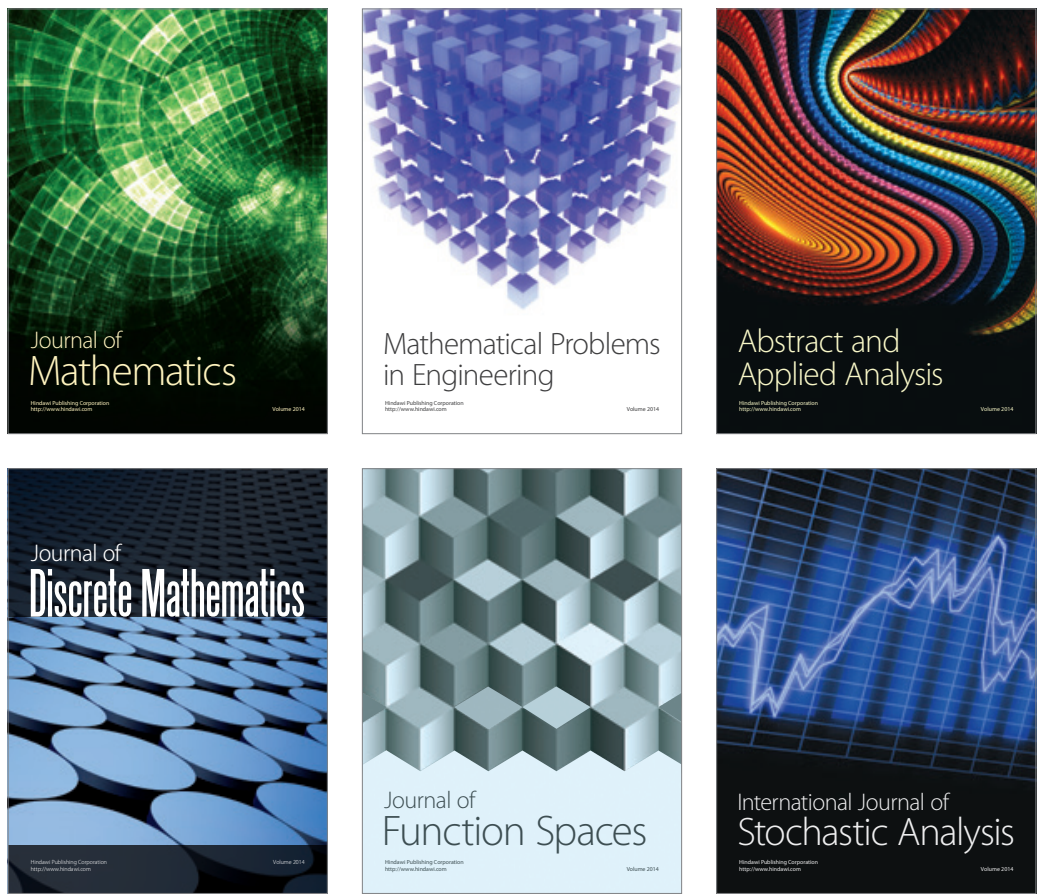

Journal of

Function Spaces

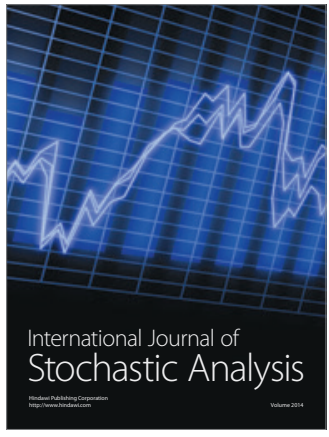

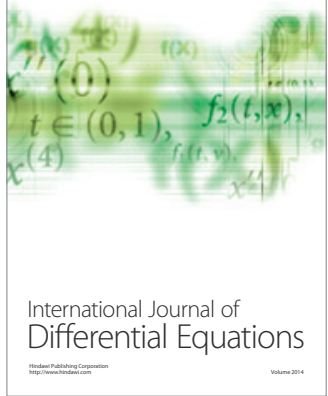
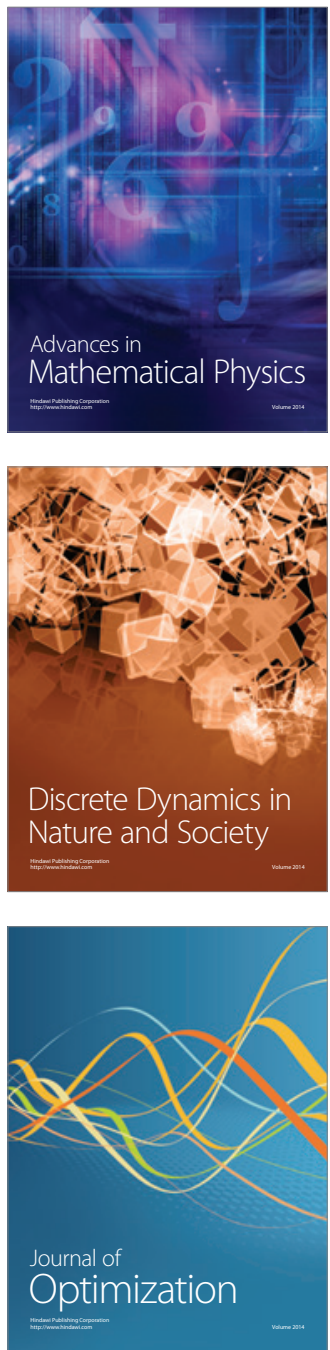